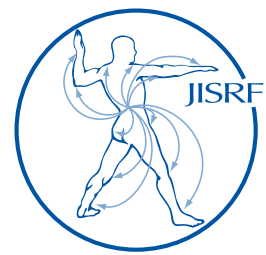

\title{
Total Hip Arthroplasty Loosening Due to Mycobacterium Tuberculosis: A Case Report and Review of the Literature
}

Tebourbi $A^{1}$, Elloumi $A^{1}$, Hadhri $K^{2}$, Salah $M^{2}$, Nefiss $M^{1}$, Bouzidi ${ }^{1}$, Kooli $M^{2}$

\begin{abstract}
Context: Prosthetic joint infection due to Mycobacterium tuberculosis (MTB) with no previous history of pulmonary or extra pulmonary tuberculosis is a rare complication.

Aims: To report the case of a patient with tuberculous mycobacterial prosthetic hip infection, 14 years after surgery for post traumatic osteoarthritis, with no previous history of tuberculosis.

Methods: A 46-year-old male presented with acetabular loosening of a cemented total hip arthroplasty with normal biologic parameters. A one stage revision surgery was planned. Intraoperative findings suggested mycobacterial tuberculous infection with presence of periacetabular yellowish rice-shaped granules.
\end{abstract}

Results: A one-stage prosthesis exchange was performed; Culture on Löwenstein-Jensen medium grew MTB days after inoculation and histological examination confirmed tuberculous infection. Patient was treated with antituberculous agents for 12 months with optimal clinical and biological response and no prosthetic loosening signs at two year follow up.

Conclusions: Total hip arthroplasty loosening due to mycobacterium tuberculosis is a rare entity, which should be considered even when no inflammatory signs are shown. Discovery of yellowish riceshaped granules is suggestive of periprosthetic tuberculosis. Management of prosthetic joint infection due to M.tuberculosis must involve both medical and surgical therapy.

Keywords: total hip replacement; prosthesis loosening; mycobacterium tuberculosis Level of Evidence: AAOS Therapeutic Level IV

1 Anis Tebourbi, MD; Ahmed Elloumi, MD; Mouadh Nefiss, MD; Ramzi Bouzidi, MD

Department of Orthopedics and Traumatology, Mongi Slim Hospital, 2046 La Marsa, Tunisia

2 Khaled Hadhri, MD; Mohamed Ben Salah, MD; Mondher Kooli, MD Department of Orthopedics and Traumatology, Charles Nicolle Hospital, Boulevard 9 Avril, 1006 Tunis Tunisia

(Direct reprint requests to Khaled Hadhri) (c) 2017 Tebourbi, Elloumi, Hadhri, Salah, Nefiss, Bouzidi, Kooli. All rights reserved.

Authors retain copyright and grant the journal right of first

publication with the work. Reconstructive Review is an open ac- open ACCEss cess publication and follows the Creative Commons Attribution-

NonCommercial CC BY-NC. This license allows anyone to download works, build upon the material, and share them with others for non-commercial purposes as

long as they credit the senior author, Reconstructive Review, and the Joint Implant Surgery \& Research Foundation (JISRF). An example credit would be: "Courtesy of (senior author's name), Reconstructive Review, JISRF, Chagrin Falls, Ohio". 


\section{Introduction}

Extrapulmonary tuberculosis is observed in about $20 \%$ of the total cases $[\underline{1}, \underline{2}]$. Among extrapulmonary cases approximately $10 \%$ are bone and joint infections, with peripheral arthritis being responsible for $30 \%$ of osteoarticular tuberculosis [1-4]. Usually a single joint is involved, with the hip joint being the most common [4].

Primary tubercular osteo-arthritis is well known, while periprosthetic tubercular infections are uncommon.

Prosthetic joint infection (PJI) due to MTB with no previous history of pulmonary or extra pulmonary tuberculosis is an extremely rare complication. There are only 39 cases reported in the literature.

We report the case of a patient with MTB PJI complicating a hip arthroplasty, 14 years after surgery for posttraumatic osteoarthritis, with no previous history of tuberculosis.

\section{Case Report}

A 46-year-old male was admitted to our institution for acetabular loosening of a cemented total hip arthroplasty (THA) (figure1). The arthroplasty was performed 14 years previously following a diagnosis of left hip osteoarthritis after nonoperative treatment of acetabular posterior wall fracture.

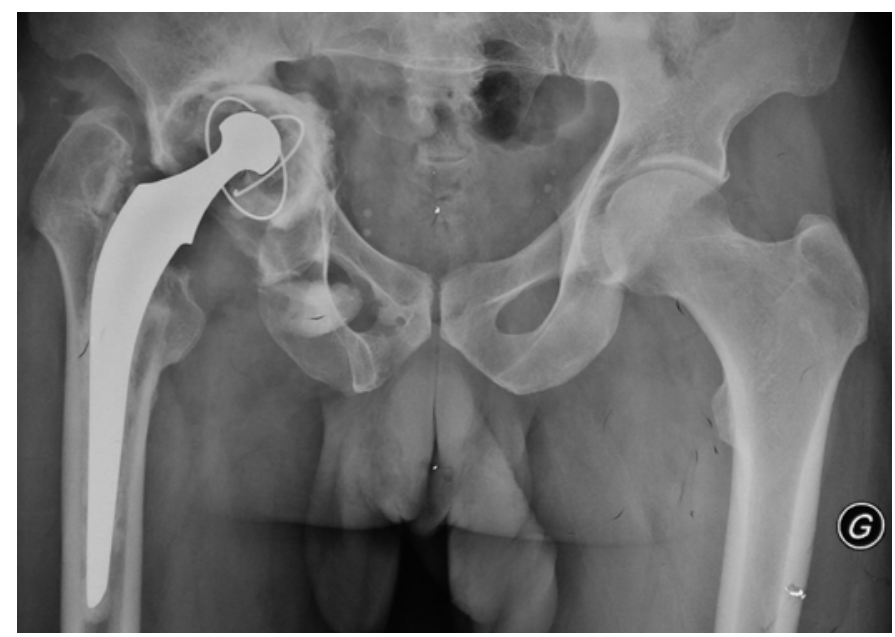

Figure 1. Initial radiographs showing acetabular loosening of left hip arthroplasty with cranial and medial migration of the cup.

On presentation the patient complained of pain and limitation of movement of the left hip. No fever or swelling around the hip was noted on admission. Chest radiograph was normal. There was no history of prior MTB infection. There was no known history of contact with MTP infection. Blood investigations demonstrated white blood cells (WBC): $7.3 \mathrm{~K} / \mu \mathrm{l}$, hematocrit (Hct): $33.6 \%$, hemoglobin
(HGB): 12g/dl, erythrocyte sedimentation rate (ESR): 36 $\mathrm{mm} / \mathrm{hr}$ and C-reactive protein (CRP): $0.02 \mathrm{mg} / \mathrm{dl}$.

Pelvic radiograph showed acetabular cup loosening with implant medial and cranial migration and no evidence of stem loosening. Revision of the hip arthroplasty was planned because of suspected asceptic loosening.

Intraoperatively, yellowish rice-shaped granules were discovered around the acetabulum, which were withdrawn along with synovium fluid for culture and histopathologic examination (Figure 2).

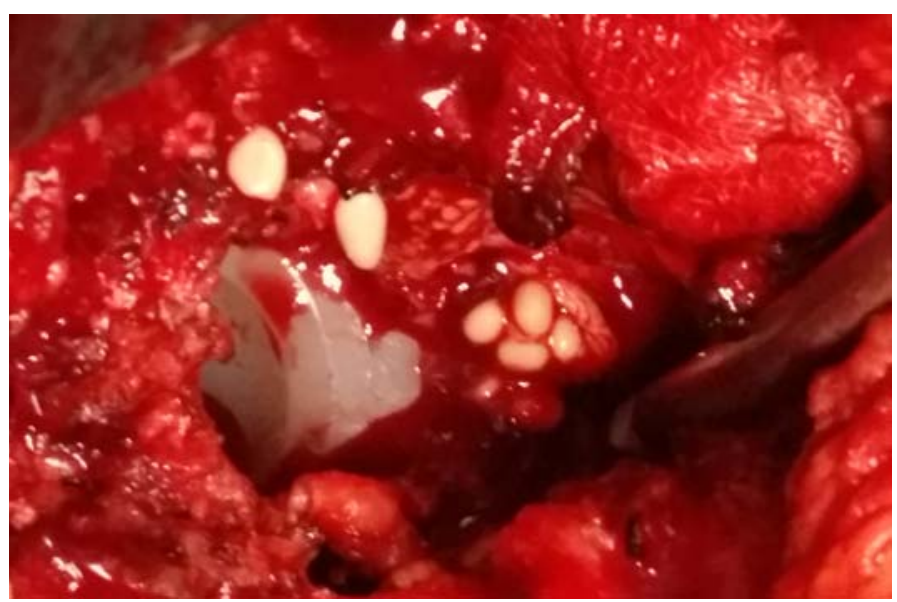

Figure 2. Peroperative finding, yellowish rice-shaped granules discovered around the acetabulum.

The prosthesis was removed, total synovectomy was done, and total hip replacement, using acetabular reinforcement device with morsellised grafts consisted of autogenous bone chips from the iliac crest, was performed.

Culture on Löwenstein-Jensen medium grew MTB days after inoculation.

Histological examination showed chronic granulomatous inflammation with granuloma formation in the presence of multinucleated giant cells, epithelioid histiocytes, and central noncaseating necrosis.

After cultures were available the patient was commenced on a combination of four antituberculous agents (rifampicin, isoniazid, ethambutol, pyrazinamide), but developed digestive and visual intolerance to ethambutol and pyrazinamide after the first week. He then continued with only rifampicin and isoniazid for 12 months.

Clinically the patient's pain improved. Full range motion was obtained after 3 months and pelvic radiograph showed no signs of prosthetic loosening after two years follow up.

\section{Discussion}

Prosthetic joint infection is a serious complication of joint arthroplasty. In patients with joint replacement, the 
Table1. Summuary of the reported cases in the literature

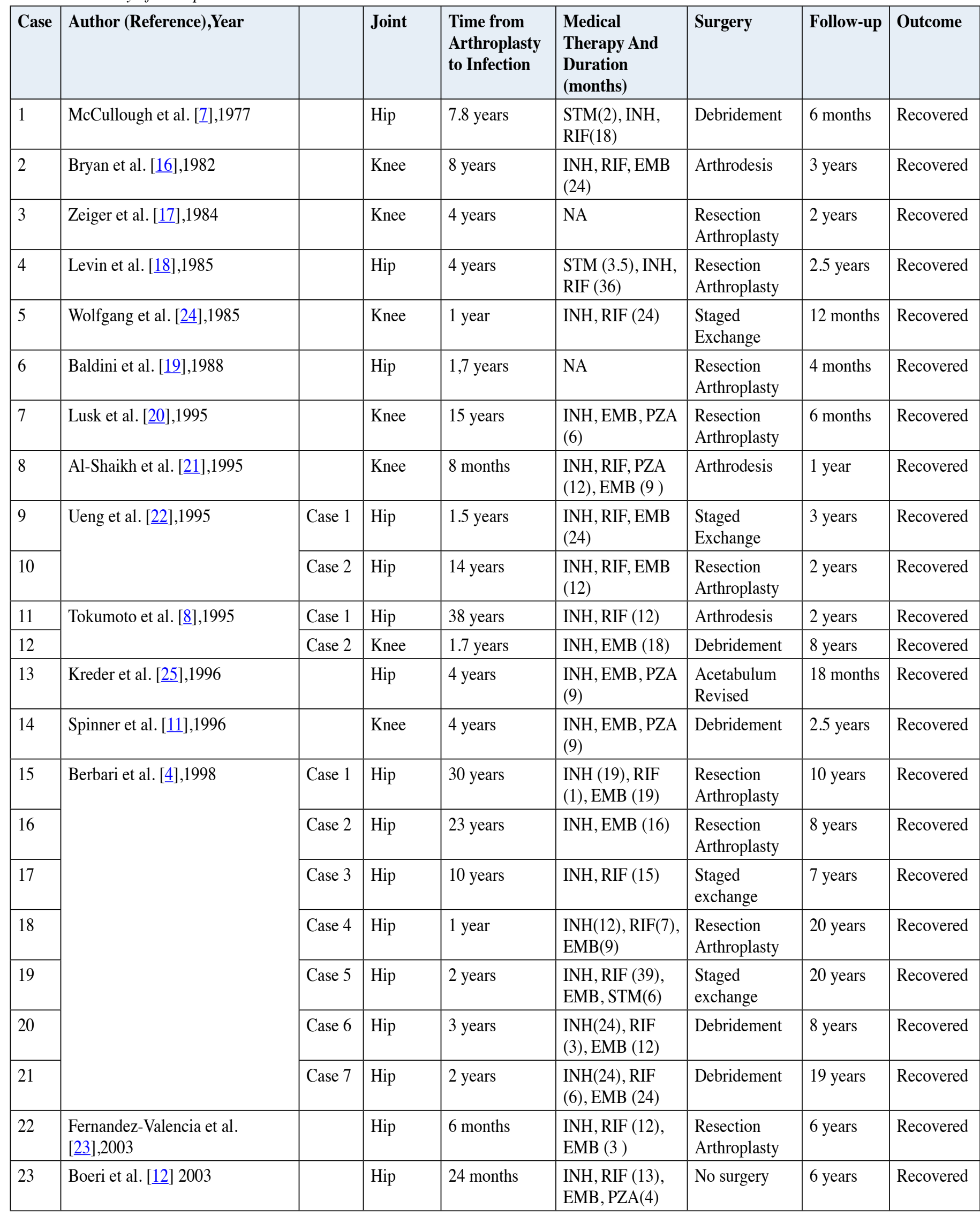

(Table 1 continued on next page) 
(Table 1 continued)

\begin{tabular}{|c|c|c|c|c|c|c|c|c|}
\hline Case & Author (Reference),Year & & Joint & $\begin{array}{l}\text { Time from } \\
\text { Arthroplasty } \\
\text { to Infection }\end{array}$ & $\begin{array}{l}\text { Medical } \\
\text { Therapy And } \\
\text { Duration } \\
\text { (months) }\end{array}$ & Surgery & Follow-up & Outcome \\
\hline 24 & \multirow[t]{3}{*}{ Marmor et al. [13],2004 } & Case 1 & Knee & 3 months & $\begin{array}{l}\text { INH, RIF, PZA } \\
\text { (6) }\end{array}$ & $\begin{array}{l}\text { Revision } \\
\text { Arthroplasty }\end{array}$ & 7 years & Recovered \\
\hline 25 & & Case 2 & Knee & 2 months & $\begin{array}{l}\text { INH, RIF, PZA } \\
\text { (6) }\end{array}$ & $\begin{array}{l}\text { Revision } \\
\text { Arthroplasty }\end{array}$ & 5 years & Recovered \\
\hline 26 & & Case 3 & Knee & 4 months & $\begin{array}{l}\text { INH, EMB, PZA } \\
\text { (8) }\end{array}$ & Debridement & 18 months & Recovered \\
\hline 27 & Shanbhag et al. [14],2007 & & Hip & 14 months & $\begin{array}{l}\text { RIF, EMB, PYR, } \\
\text { PZA (12) }\end{array}$ & No surgery & 18 months & Recovered \\
\hline 28 & Wang et al.[1이 2007 & & Knee & 3 years & $\begin{array}{l}\text { INH, RIF, EMB, } \\
\text { PZA }\end{array}$ & Debridement & Died & \\
\hline 29 & Khater et al.[26] 2007 & & Knee & 3 months & INH, EMB(18) & $\begin{array}{l}\text { Rev } \\
\text { Arthroplasty }\end{array}$ & 1,5 years & Recovered \\
\hline 30 & Lee et al. [15], 2009 & & Knee & 2 months & $\begin{array}{l}\text { RIF, INH, EMB } \\
(12)\end{array}$ & No surgery & 13 months & Recovered \\
\hline 31 & \multirow[t]{5}{*}{ Carrega et al. [9], 2009} & Case 1 & Knee & NA & $\begin{array}{l}\text { RIF, INH, EMB } \\
(12)\end{array}$ & No surgery & 12 months & Recovered \\
\hline 32 & & Case 2 & Hip & 1 month & $\begin{array}{l}\text { RIF, INH, EMB } \\
\text { (5) }\end{array}$ & No surgery & 12 months & Recovered \\
\hline 33 & & Case 3 & Hip & NA & $\begin{array}{l}\text { RIF, INH, EMB } \\
(9)\end{array}$ & No surgery & 13 months & Recovered \\
\hline 34 & & Case 4 & Knee & 2 months & $\begin{array}{l}\text { RIF, INH, EMB } \\
(12)\end{array}$ & Debridement & 6 months & Recovered \\
\hline 35 & & Case 5 & Hand & 2 years & $\begin{array}{l}\text { RIF, INH(12), } \\
\text { EMB, PZA(2) }\end{array}$ & Debridement & 1 years & Recovered \\
\hline 36 & Mete et al. []], 2012 & & Knee & NA & $\begin{array}{l}\text { RIF, INH(12), } \\
\text { EMB, PZA(2) }\end{array}$ & $\begin{array}{l}\text { Staged } \\
\text { exchange }\end{array}$ & 12 months & Recovered \\
\hline 37 & Kofteridis et al.[3]], 2013 & & Hip & 30 months & $\begin{array}{l}\text { RIF, INH(12), } \\
\text { EMB, PZA(2) }\end{array}$ & $\begin{array}{l}\text { Revision } \\
\text { Arthroplasty }\end{array}$ & 2 years & Recovered \\
\hline 38 & Burger et al.[]‥ 2013 & & Knee & $2 y$ & $\begin{array}{l}\text { RIF, INH, EMB, } \\
\text { PZA(18) }\end{array}$ & $\begin{array}{l}\text { Revision } \\
\text { Arthroplasty }\end{array}$ & 2 years & Recovered \\
\hline 39 & Montano et al.[27]]. 2014 & & Hip & $2 y$ & $\begin{array}{l}\text { RIF, INH(12), } \\
\text { EMB, PZA(2) }\end{array}$ & $\begin{array}{l}\text { Revision } \\
\text { Arthroplasty }\end{array}$ & 3,5 years & Recovered \\
\hline 40 & Present Case. 2016 & & Hip & $14 \mathrm{y}$ & RIF, INH(12) & $\begin{array}{l}\text { Acetabulum } \\
\text { Revised }\end{array}$ & 1 year & Recovered \\
\hline
\end{tabular}

infection rate is estimated to be less than $1 \%$ for the hip and $2 \%$ for knees $[\underline{5}, \underline{6}]$. The common bacterial causes of prosthesis joint infections are coagulase-negative Staphylococcus, Staphylococcus aureus, aerobic Gram-negative bacilli and anaerobes. M.tuberculosis is a rarely seen cause of prosthesis infection.

PJI due to MTB with no previous history of pulmonary or extra pulmonary TB is a rare complication; only 40 cases are reported in literature (table1). In 1977, McCullough reported the first case of tuberculous infection of a THA seven years after implantation []].
It can result from either local reactivation or less often from hematogenous spread. Local reactivation can occur as long as 38 years after initial infection and may be related to trauma associated with surgery. The risk for reactivation has been reported to be between $0 \%$ and $31 \%$, with TKA (27\%) more at risk than THA (6\%). [4]. As for hematogenous spread, reactivation at a latent tuberculous site such as the lung, kidney, or mesenteric lymph nodesresults in subsequent seeding of the prosthesis [ $[$ ] .

From the 39 cases reported in the literature, several clinical features emerge. In the majority of these cases, the pa- 
tients were over age 50 years (range $25-85$ years) and were female (30 female and 10 males). The hip joint was involved in 22 cases and the knee in 18 cases. The time from prosthesis implantation to manifestations of infection was variable, ranging from 1 month [9] to 38 years []‥ Patients usually presented with non specific clinical findings of an

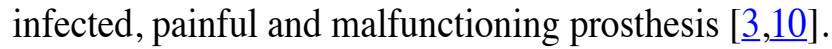

Inflammatory markers including erythrocyte sedimentation rate (ESR) and CRP were usually elevated to some degree but are non-specific.

In contrast to the reported cases in literature, our patient only suffered from hip pain and presented no inflammatory signs, no fever, and no signs of any infection. Even inflammatory markers (CRP) were found negative. Pain was most likely due to mechanical loosening rather than the infectious process itself; the macroscopic aspect of the intraarticular granuloma was thought to be related to both tuberculous infection and polyethylene induced synovitis.

Diagnosis proved difficult in nearly all the cases. Most importantly this can be attributed to the fact that the initial microbiological investigations did not include specific requests for tuberculosis; which depends on culture and histopathologic examination of tissue; that may reveal acidfast organisms or caseating granulomas. But granulomas can also represent a reaction to the prosthesis or polyethylene wear debris. Acid-fast stains of the joint fluid are positive in $20-25 \%$ of the cases, while cultures are positive in approximately 60 to $80 \%$; histological features are non specific $[\underline{3}, \underline{10}]$.

In our case, the discovery of the rice-shaped granules lead us to think of a septic loosening, and therefore to investigate for atypical organisms. Medical management with multidrug antituberculous therapy according to proven sensitivities remains the mainstay of treatment. Duration of therapy is controversial with five months the minimum [9]. The average duration was twelve months.

Surgical treatment depends on the quality of component fixation. If it remains stable components may be retained and medical treatment with or without debridement may suffice. This strategy was done and successful in fifteen cases $[\underline{4}, \underline{7-10}, \underline{11-15}]$. In the presence of component loosening or secondary bacterial infection, removal and staged revision is advised and achieved satisfactory outcomes in twelve cases $[\underline{3}-\underline{6}, \underline{13}, \underline{22}, \underline{24}-\underline{27}]$. In twelve other cases, excision arthroplasty was performed $[\underline{4}, \underline{8}, \underline{16}-\underline{23}]$. Staged arthrodesis was done in three cases $[\underline{8}, \underline{16}, \underline{21}]$ and is aimed to eliminate the disease but is not without functional problems.

In the present case, acetabular revision was combined with medical management and achieved satisfactory outcomes at 18 months followup.

\section{Conclusions}

In conclusion, the present case indicates that in any case of loosening, even when no inflammatory signs are shown, synovium should be routinely examined for pathogenic bacteria including $\mathrm{M}$ Tuberculosis, especially when there are atypical features. We can also consider that discovery of such yellowish rice-shaped granules is an indicator to investigate for tuberculosis.

Furthermore, the treatment of the prosthetic joint infection due to M.tuberculosis must involve both medical and surgical approach.

\section{Disclosure}

The authors declare that there is no conflict of interest regarding the publication of this paper. For full disclosures refer to last page of this journal.

\section{References}

1. Fitzgerald DW, Sterling TR, Haas DW. Mycobacterium tuberculosis. In Mandell, Douglas, Bennett's Principles and Practice of Infectious Diseases, 7th ed. Philadelphia: Elsevier Churchill Livingston, 2010;3129-3163

2. Peto HM, Pratt RH, Harrington TA, LoBue PA, Armstrong LR. Epidemiology of extrapulmonary tuberculosis in the United States, 1993-2006. Clin Infect Dis. 2009;49: 1350-1357.

3. Kofteridis DP, Dimopoulou D, Maraki S et al. Delayed-Onset Mycobacterium tuberculosis Prosthetic Joint Infection after Hip Hemiarthroplasty: A Case Report and Review of the Literature. Clin Microbial. 2013;2:114.

4. Berbari EF, Hanssen AD, Duffy MC, Steckelberg JM, Osmon DR. Prosthetic joint infection due to Mycobacterium tuberculosis: a case series and review of the literature. Am J Orthop 1998; 27:219-27.

5. Mete B, Yemisen M, Aydin S et al. An unusual cause of prosthetic joint infection: Mycobacterium tuberculosis. J Microbiol Infect Dis. 2012;2: 72-75

6. Burger JD, De Jongh $\mathrm{H}$ et al. Total knee replacement infected with Mycobacterium tuberculosis: A case study and review of the literature. SA Orthop J. 2013:12(2):64-68.

7. McCullough CJ. Tuberculosis as a late complication of total hip replacement. Acta Orthop Scand. 1977;48:508-10.

8. Tokumoto JI, Follansbee SE, Jacobs RA. Prosthetic joint infection due to Mycobacterium tuberculosis: Report of three cases. Clin Infect Dis. 1995; 21:134-6.

9. Carrega G, Bartolacci V, Burastero G et al. Prosthetic joint infections due to Mycobacterium tuberculosis: A report of 5 cases. Int J Surg Case Rep. 2013;4:178181.

10. Wang PH, Shih KS, Tsai CC, Wang HC. Pulmonary tuberculosis with delayed tuberculosis infection of total knee arthroplasty. J Formos Med Assoc. 2007;106:8285 .

11. Spinner RJ, Sexton DJ, Goldner RD, Levin LS. Periprosthetic infections due to Mycobacterium tuberculosis in patients with no prior history of tuberculosis. J Arthroplasty 1996;11:217-222.

12. Boeri C, Gaudias J, Jenny JY. Total hip replacement prosthesis infected by Mycobacterium tuberculosis. Rev Chir Orthop. 2003;89:163-6.

13. Marmor M, Parnes N, Dekel S. Tuberculosis infection complicating total knee arthroplasty: report of 3 cases and review of the literature. J Arthroplasty 2004; 19:397-400.

14. Shanbhag V, Kotwal R, Gaitonde A, Singhal K. Total hip replacement infected with Mycobacterium tuberculosis A case report with review of literature. Acta Orthop Belg 2007;73:268-274.

15. Lee CL, Wei YS, Ho YJ, Lee CH. Postoperative Mycobacterium tuberculosis infection after total knee arthroplasty. Knee 2009;16: 87-89.

16. Bryan WJ, Doherty JH Jr, Sculco TP. Tuberculosis in a rheumatoid patient. A case report. Clin Orthop. 1982; 171:206-8.

17. Zeiger LS, Watters W, Sherk H. Scintigraphic detection of prosthetic joint and soft tissue sepsis secondary to tuberculosis. Clin Nucl Med. 1984;9:638-9.

18. Levin ML. Miliary tuberculosis masquerading as late infection in total hip replacement. Md Med J. 1985;34:153-5. 
19. Baldini N, Toni A, Greggi T, Giunti A. Deep sepsis from Mycobacterium tuberculosis after total hip replacement. Case report. Arch Orthop Trauma Surg. 1988;107:186-8.

20. Lusk RH, Wienke EC, Milligan TW, Albus TE. Tuberculous and foreign-body granulomatous reactions involving a total knee prosthesis. Arthritis Rheum 1995; 38:1325-7.

21. Al-Shaikh R, Goodman SB. Delayed onset Mycobacterium tuberculosis infection with staphylococcal superinfection after total knee replacement. Am J Orthop 1995;32:302-5.

22. Ueng WN, Shih $\mathrm{CH}$, Hseuh S. Pulmonary tuberculosis as a source of infection after total hip arthroplasty. A report of two cases. Int Orthop. 1995;19:55-9.
23. Fernandez-Valencia JA, Garcia S, Riba J. Presumptive infection of a total hip prosthesis by Mycobacterium tuberculosis: A case report. Acta Orthop Belg. 2003; 69:193-6.

24. Wolfgang GL. Tuberculosis joint infection following total knee arthroplasty. Clin Orthop. 1985;201:162-6.

25. Kreder HJ, Davey JR. Total hip arthroplasty complicated by tuberculous infection. J Arthroplasty 1996;11:111-4.

26. Khater FJ, Samnani IQ, Mehta JB, Moorman JP, Myers JW. Prosthetic joint infection by Mycobacterium tuberculosis: an unusual case report with literature review. South Med J. 2007;100:66-69.

27. Builes-Montaño C, Valderrama C, Pérez C et al. Infección por Mycobacterium tuberculosis en una prótesis de cadera, reporte de un caso y revisión de la literatura. Rev Chilena Infectol. 2014;31(4): 473-6 